\title{
Impact of artificial intelligence adoption on online returns policies
}

\author{
Guangyong Yang ${ }^{1} \cdot$ Guojun $\mathrm{Ji}^{1} \cdot \mathrm{Kim}$ Hua $\operatorname{Tan}^{2}$ \\ Published online: 10 April 2020 \\ (c) The Author(s) 2020
}

\begin{abstract}
The shift to e-commerce has led to an astonishing increase in online sales for retailers. However, the number of returns made on online purchases is also increasing and have a profound impact on retailers' operations and profit. Hence, retailers need to balance between minimizing and allowing product returns. This study examines an offline showroom versus an artificial intelligence (AI) online virtual-reality webroom and how the settings affect customers' purchase and retailers' return decisions. A case study is used to illustrate the AI application. Our results show that adopting artificial intelligence helps sellers to make better returns policies, maximize reselling returns, and reduce the risks of leftovers and shortages. Our findings unlock the potential of artificial intelligence applications in retail operations and should interest practitioners and researchers in online retailing, especially those concerned with online returns policies and the consumer personalized service experience.
\end{abstract}

Keywords Artificial intelligence · Returns policies · Offline showroom · Fit · Exchange

\section{Introduction}

Concerning products sold online that have nondigital attributes, the most significant downside is that consumers' cognition comes from looking at pictures rather than the actual items. For example, apparel products sold online are affected by the size differences, which increase product uncertainty regarding the fit, and the color differences between the items and the

Kim Hua Tan

kim.tan@nottingham.ac.uk

Guangyong Yang

gyyang@xmu.edu.cn

Guojun Ji

jiking@xmu.edu.cn

1 School of Management, Xiamen University, Xiamen 361005, Fujian, China

2 Nottingham University Business School, Jubilee Campus, Nottingham, UK 
pictures. To induce apprehensive consumers to make a purchase, especially under no reason returns policy and competitive pressure, many online retailers/sellers may offer full (or nearly full) refunds. Examples of sellers providing full refunds include Zappos.com and Saks Fifth Avenue (Altug and Aydinliyim 2016). It is worth noting, however, that returning purchased products is costly to both consumers and sellers. Even though the consumer returning a product can make a full refund claim, she must pay the return cost. For example, purchasing return and exchange freight insurance has becoming a necessary guarantee for consumers to buy online (Chen 2019). In addition, consumers may incur packaging and shipping costs associated with returning an item. It has been reported that approximately $72 \%$ of Chinese consumers hope to purchase online and return offline, which reveals that consumers with high return cost may be reluctant to purchase products online (McKinsey 2015). However, consumer returns substantially aggravate online operation and erode sellers' profits, especially those returns that have no defects. Sprague et al. (2008) report that about $95 \%$ of returns have no defects. Furthermore, Gartner's survey of 300 retailers around the world showed that more than 52\% of returns can only be salvaged (Overseas Chinese News Network 2015). All this shows that the depreciation of returns over time may further lower the profit margin the seller can expect. Consequently, finding the right balance between minimizing returns and providing full refunds is extremely challenging. This paper focuses on two types of operational innovation adopted by online sellers: an offline showroom focusing on providing a physical experience, and artificial intelligence focusing on offering a personalized virtual-reality experience.

As commonly practiced, creating an offline showroom is widely deemed a crucial measure in reducing returns by preventing consumers from purchasing products that they realize afterwards they dislike. For example, the leading online-first Warby Parker creates showrooms in some markets, and returns in the trading areas of the showrooms decrease by $1 \%$ (Bell et al. 2018). As reported in Pauwels and Neslinb (2015), adding an offline channel can increase the total revenue of omnichannel sellers by nearly $20 \%$. Furthermore, a survey of 479 managers conducted by RetailWire revealed that the consumer experience in the showroom is the most important ingredient of consumer satisfaction, ahead of product assortment and promotion (Iyer and Kuksov 2012).

Aside from offline showrooms, the adoption of artificial intelligence (AI) is currently emerging to assist online consumers when purchasing products. This paper examines three types of artificial intelligence technologies: virtual fitting technologies, chatbots, and intelligent recommendation agents.

(1) Artificial intelligence virtual fitting technologies.

To lower the matching uncertainty of online clothing sales, previous and existing virtual fitting technologies focus on letting consumers ascertain the effectiveness of matching different clothing items. However, artificial intelligence virtual fitting technology, which uses data and algorithms, helps sellers quickly and accurately profile the consumer's clothing preferences, and recommend the style and products that consumers are actually interested in, which can be regarded as matching the artificial intelligence recommendation. For example, the leading online seller Haomaiyi develops virtual fitting technologies to provide each consumer with an exclusive artificial intelligence fashion consultant, which helps to convert $12.4 \%$ of fitting consumers into purchasers and reduce the return rate of some brands by about $30 \%$ (You 2017). Other examples include Stitch Fix, an online personal styling service that relies on artificial intelligence to accurately unlock consumer preferences as well as product trends, and to specialize in clothing matching subscription sales; and Modiface, which adopts artificial intelligence to provide a virtual trial experience for Sephora (Hua Ying capital 2018) and 
online retail that provides virtual fitting-room technologies to increase the probability of purchases and reduce the probability of returns (Gallino and Moreno 2018).

(2) Artificial intelligence chatbots.

Artificial intelligence chatbots that efficiently scan databases using sophisticated natural language processing tools are being adopted to enhance consumer engagement, and provide a higher quality of services and product fit information (Cohen 2017). In addition, AI chatbots are as effective as proficient workers and four times more effective than inexperienced workers, which may enhance consumer purchases (Luo et al. 2019).

(3) Intelligent recommendation agents.

Using data-driven recommendation algorithms can result in a nearly $14 \%$ increase in profits for an online retailer (Ettl et al. 2019). In addition, employing intelligent recommendation agents with collaborative filtering can effectively recommend better fit products (Alexandrescu et al.2017). Although these artificial intelligence applications cannot entirely eliminate fit uncertainty caused by nondigital attributes of products, creating an offline showroom allows consumers to ascertain product fit information prior to making a purchase. However, the consumer must incur offline visiting costs, which may reduce the customer's willingness to engage in this experience. An artificial intelligence virtual-reality experience may greatly lower rather than eliminate product fit uncertainty, and the consumer can have experience from online channels without having to pay, or with having a lower cost; in other words, adopting artificial intelligence not only increases customer attachment to the product but also rather objectively recommends better-matching exchanges. In general, both operation innovations - offline showrooms and virtual-reality showrooms-generally provide contrasting experiences.

Furthermore, existing work that mainly empirically and experimentally examines how AI adoption affects online returns policies pays little attention to reselling returns and demand uncertainty, yet as mentioned above, reselling returns substantially complicates the operation and erodes margins, while demand uncertainty may amplify the risk of product leftover and shortage. Consequently, incorporating these considerations is the focus of this paper. Specifically, we focus on comprehensively balancing artificial intelligence adoption through a personalized virtual-reality experience that may lower product fit uncertainty, after-sales services that accurately and objectively recommend horizontally and vertically differentiated exchanges, initial stocking decision for profitability, and tractability for practical online operation. We first adopt an analytic newsvendor model to examine the effects of artificial intelligence adoption on online returns polices, then use the data from Stitch Fix to complement the analytical model, thus better guiding the recommended exchanges and coping with the challenges of fairness of consumer's purchase caused by big data killing events (that is, the seller sets prices higher for a product when consumer browsing and purchasing frequency increases).

Our results have substantial implications for online sellers. First, if the cost of consumer returns is determined to be relatively low, the consumer prefers to make an uninformed purchase directly; thus, the seller should adopt artificial intelligence to enhance a virtualreality experience that substantially lowers returns. If the consumer return cost is high, we caution that lowering consumer return costs prompts more consumers to make uninformed purchases directly, which leads to an increasing number of returns. Second, compared with not allowing returns, if the level of lessening misfit with an initial purchase or objectively recommending an exchange with a subsequent return is relatively high, adopting artificial intelligence can benefit the seller. Third, compared with a physical showroom instead of not 
allowing returns, adopting artificial intelligence expands the range of relevant parameters. Last, artificial intelligence should accurately recommend vertically differentiated exchanges with relatively high marginal profit.

The rest of the paper is organized as follows. We provide a review of related literature in Sect. 2. We present the model formulation and study providing full refunds only in Sect. 3. We then study providing an offline showroom in Sect. 4. We examine the value of artificial intelligence adoption in Sect. 5. Managerial implications for practice and for research are explored in Sect. 6. In Sect. 7, we provide concluding remarks.

\section{Literature review}

Our paper draws on the following research streams: consumer returns, product fit information, and artificial intelligence application. The first related stream of research examines consumer returns from misfit without any product defects in a single-channel setting. Chou et al. (2020) examine an optimal inventory policy in which returns are forecast to depend on past demands. Shulman et al. (2009) find that even if provision of product fit information possibly eliminates returns, returns can be part of an optimal product sales process. $\mathrm{Su}(2009)$ examines the impact of returns policies on supply chain performance. Hsiao and Chen (2012) argue that consumer returns are offered only when the high-segment consumers incur a high hassle cost. Shang et al. (2017) examine how the extent and benefit of wardrobing affect pricing decisions. Hu et al. (2019) find that ignoring returns may lead to overpricing and can cause significant revenue loss. Altug and Aydinliyim (2016) examine how consumers' discount-seeking purchase deferrals affect online returns policies. Tran et al. (2018) explore the relative preference of a quota-based policy versus a partial-refund policy. Xiao and Shi (2016) examine two revelation mechanism models of a supply chain under asymmetric information, where the retailer provides store assistance to reduce the rate of consumer returns. There are additional related studies that focus on the dual channel context, including the following: Ofek et al. (2011) examine the impact of product returns on the strategies of online retailers and brick-and-mortar retailers. Letizia et al. (2018) study how the trade-off between product marginal value and uncertainty about product fit affects the manufacturer's sales channel design. Dijkstra et al. (2017) study dynamic policies for transshipment of returns cross-channel. Most of the above studies focus on the design of returns policies in a single-channel or multichannel context. Our work extends those findings, further studying the impact of artificial intelligence adoption.

The second related stream of research examines creating offline showroom as well as product fit information. Jing (2018) examines competition between a traditional and an online retailer in the presence of showrooming. Bell et al. (2018) report that online-first retailers can realize demand and operational efficiency benefits from opening showrooms. Gao and $\mathrm{Su}$ (2017) find that physical showrooms may prompt retailers to reduce store inventory. $\mathrm{Xu}$ et al. (2017) examine the complementary and substitution impact of the tablet channel on the smartphone and PC channels. Pauwels and Neslinb (2015) assess the revenue impact of adding brick-and-mortar stores to already existing catalog and Internet channels. Avery et al. (2012) study the impact of adding retail channels on catalog sales and Internet sales. Gallino and Moreno (2018) explore how providing virtual fit information helps both customers and retailers. Generally, the above studies focused on offline showrooms and product fit information while we in particular examined the influence of offline showrooms and artificial intelligence adoption on online returns policies. Additionally, there has been recent interest 
regarding the consumer experience. Iyer and Kuksov (2012) examine how providing a shopping experience affects pricing and advertising strategies. Kumar et al. (2014) examine how personal income influences service purchase decisions. We incorporate reselling returns and demand uncertainty into studies concerning consumer experience.

Third, our work is closely related to artificial intelligence adoption. Fosso Wamba et al. (2019) identify a set of internal and external factors related to the adoption and use of social media technologies by the New South Wales state emergency service in Australia. Fan et al. (2018) examine the factors impacting healthcare professionals to adopt an artificial intelligence-based medical diagnosis support system. Luo et al. (2019) find that artificial intelligence chatbots are as effective as proficient workers and four times more effective than inexperienced workers in engendering customer purchases. Leung et al. (2018) examine how artificial intelligence automation removes the possibility for consumers to internalize the outcomes of the consumption experience. Alexandrescu et al. (2017) find that employing artificial intelligence agents that rely on dynamically weighted graphs can effectively recommend better fit products. Sivamani et al. (2018) examine a decision support system for the nutritional management of livestock using the Bayesian model based on fuzzy rules. Li et al. (2018) explore how demand chain management can perform better in the electronic commerce environment by studying website behavior data and using data analytics tools. Ettl et al. (2019) examine how to recommend a personalized discounted product bundle to an online shopper through data-driven algorithms. These studies did not involve reselling returns whereas the present paper complements this literature by analytically examining the impact of both artificial intelligence adoption and reselling returns on online returns policies.

To summarize the contribution of our work relative to the existing literature, there has been no research that specifically focuses on supplementing online returns policies, creating offline showrooms, and adopting artificial intelligence; our work incorporates these three aspects.

\section{The model}

We consider an online monopolist seller who sells a product. For brevity, the entire sales horizon is partitioned into two periods: period $t_{1}$ at regular sales price $p$ and period $t_{2}$ at salvage value $s$. The initial inventory and unit procurement cost to the seller are $q$ and $c$, respectively. We characterize market demand as a mass of infinitesimal consumers, and each consumer has the most unit demand, which shows that the impact of the individual consumer on the total demand can be negligible. The total number of consumers who decide to make a purchase in period $t_{1}$ is a random variable $x \geq 0$ with distribution function $F(\cdot)$, complementary $\operatorname{cdf} \bar{F}(\cdot)=1-F(\cdot)$ and density function $f(\cdot)$. Intuitively, consumers are unsure whether the product meets their preferences. Let $m \in(0,1)$ denote the probability that a consumer really likes the product. Liking the product derives a value $v$ from it, and a value of zero otherwise. In period $t_{2}$, the seller salvages all leftovers at discount price $s$ through other channels (markets); in other words, these leftovers may be resold to a liquidator who pays only a small fraction of the original value ( $\mathrm{Ng}$ and Stevens 2015). To a certain extent, a positive value of $s$ reflects the seller's capability to resell the returns through secondary channels (Letizia et al. 2018; Shulman et al. 2009). For instance, online seller Jingdong.com auctions returns on Treasure Island web, which can be considered a clearing channel. We make the usual assumption that $s \leq c$. 
We assume that the seller offers full refunds and consumers are allowed to return the product only once. Consumers can discover and learn the product fit gap only after receiving and sometimes using the product. In the case of a misfit, the consumers return the products and claim a full refund $p$. However, consumers incur costs $t$ associated with returning items (Altug and Aydinliyim 2016; Dukes and Zhu 2019). Furthermore, value depreciation of returns over time may lower the seller's profit margin. For simplicity, products unsold in period $t_{1}$ are labeled as new products, and products sold but returned are called returns. We assume that $v$ is sufficiently high such that all consumers get a non-negative surplus. A summary of our notation is provided in "Appendix A".

\subsection{Benchmark model}

As a benchmark model, we first consider the setting without allowing returns; that is, each consumer will make an uninformed purchase, then the total demand is $x$. The seller's expected profit is given as

$$
\Pi_{B}(q)=p E \min (q, x)+s[q-E \min (q, x)]-c q .
$$

Differentiating $\Pi_{B}(q)$ w.r.t. $q$, we can calculate the optimal quantity. The first-order condition (sufficient owing to profit function concavity) yields $q_{B}^{*}=\bar{F}^{-1}[(c-s) /(p-s)]$, then the resulting optimal profit is given by $\Pi_{B}^{*}=(p-s) \int_{0}^{q_{B}^{*}} x f(x) d x$.

\subsection{Providing full refunds}

Common practice in many industries, such as electronics, household, and fashion reveals that the vast majority of returns are for full (or approximately full) refunds because of competitive pressure as well as no reason returns policies. When the seller provides full refunds for returns, intuitively, the consumer is always capable of returning it and claiming a full refund upon finding product misfit. Hence, the total demand is also $x$.

\subsubsection{Salvaging all returns ( $R$ policy)}

When all returns are salvaged in period $t_{2}$, the seller's expected profit can be expressed as

$$
\Pi_{R}(q)=p E \min (q, x)-(p-s)(1-m) E \min (q, x)+s[q-E \min (q, x)]-c q .
$$

In Eq. (2), the first item represents the revenue from the products sold, the second item indicates the loss from consumers returning products, the third item captures revenues from salvaging new products, and the last item is the procurement cost.

In a similar fashion, we can immediately get the optimal quantity $q_{R}^{*}=\bar{F}^{-1}\left[\frac{c-s}{(p-s) m}\right]$, and the resulting optimal profit $\Pi_{R}^{*}=(p-s) m \int_{0}^{q_{R}^{*}} x f(x) d x$.

Proposition 1 The seller's optimal profit $\Pi_{R}^{*}$ is increasing convex in $m$.

See “Appendix B" for the proof.

Proposition 1 reveals that, as the probability $m$ of a consumer really liking the product increases, more consumers buy and keep the product, decreasing returns and risk of leftovers; hence, we expect the optimal quantity and resulting optimal profit to increase. 


\subsubsection{Quick resale of returns ( $Q$ policy)}

Assumption 1 When returns can be resold quickly, the sales price of returns is the same as that of the new products.

Assumption 1 argues that when the seller can resell the returns quickly, these returns can be resold as new products (i.e., the sales price of returns is also $p$ ). This assumption is a reasonable approximation, as follows: first, we do not consider returns caused by product damage, end of lifecycle and speculation, but mainly focus on the returns due to misfit; second, the return cost is incurred by consumers because the reason for the return is on the consumer's side; third, through simple reprocessing (such as repacking), the performance and intrinsic value of returns are the same as that of new products, so that consumers have the same willingness to pay for both new products and returns. Likewise, we assume that the cost of reprocessing returns is negligible as in Akçay et al. (2013). Taken together, returns can be resold as new products. A closely related paper is that by Crocker and Letizia (2014), who also assumed the resale of returns at the same sales price of new products.

Next, we characterize the seller's decision problem. First, when demand $x \leq q$, the number of products sold is $x$, and the number of returns is $(1-m) x$ because the fraction $(1-m)$ of sales turns into returns. Interestingly, even if returns can be recovered quickly and resold in period $t_{1}$, because demand is less than the stocking quantity, consumers no longer purchase returns; thus, all returns can eventually be salvaged in period $t_{2}$. Second, when $x>q$, the number of sales is $q$, the number of returns is $S_{0}=(1-m) q$, and the remaining $D_{0}=x-q$ will cause consumers to encounter shortages when they buy products. Comparing $S_{0}$ and $D_{0}$, if $x<[1+(1-m)] q$, then $S_{0}>D_{0}$, the number sold to the remaining consumers encountering shortages is $D_{0}$, and the number of returns is $(1-m) D_{0}$; similarly, all returns will eventually be resold at a salvage value. Meanwhile, the unsold new products $S_{0}-D_{0}$ in period $t_{1}$ can also only be salvaged; if $x \geq[1+(1-m)] q$, then $S_{0} \leq D_{0}$, consumers who cannot purchase a new product (due to unavailability) will purchase a return; thus, the number sold to the remaining consumers is $S_{0}$, and the number of returns is $S_{1}=(1-m)^{2} q$; at the same time, the remaining $D_{1}=x-[1+(1-m)] q$ consumers have not yet purchased products because of shortages. Following the same logic as above, if $x<\left[1+(1-m)+(1-m)^{2}\right] q$, then $S_{1}>D_{1}$, the quantity sold to the remaining consumers is $D_{1}$ and the number of new products needed to be salvaged is $S_{1}-D_{1}$; if $x \geq\left[1+(1-m)+(1-m)^{2}\right] q$, then $S_{1} \leq D_{1}$, the number sold to the remaining consumers is $S_{1}$, the number of returns is $S_{2}=(1-m)^{3} q$, and the number of consumers who cannot purchase the product becomes $D_{2}=x-\left[1+(1-m)+(1-m)^{2}\right] q$, and so on. Essentially, all consumers may return products with a poor match, and these returns will eventually be salvaged in period $t_{2}$. Hence, the seller's profit is as follows:

$$
\begin{aligned}
\Pi_{Q}(q)= & p \int_{0}^{q} x d F(x)-(p-s) \int_{0}^{q}(1-m) x d F(x)+p \int_{q}^{+\infty} q d F(x) \\
& -(p-s) \int_{q}^{+\infty}(1-m) q d F(x)+s \int_{0}^{q}(q-x) d F(x)-c q
\end{aligned} .
$$

After calculation and arrangement, Eq. (3) becomes

$$
\Pi_{Q}(q)=(p-s) m E \min (x, q)-(c-s) q .
$$

Solving this optimization problem allows us to get the optimal quantity $q_{Q}^{*}=$ $\bar{F}^{-1}\left[\frac{c-s}{(p-s) m}\right]$, and the resulting optimal profit $\Pi_{Q}^{*}=\Pi_{Q}\left(q_{Q}^{*}\right)$. 
Proposition 2 The seller's optimal quantity and profit are the same under $Q$ policy and $R$ policy, but both are lower than not allowing returns policy, i.e., $q_{Q}^{*}=q_{R}^{*}<q_{B}^{*}$, and $\Pi_{Q}^{*}=\Pi_{R}^{*}<\Pi_{B}^{*}$.

Proposition 2 highlights that even though the seller is capable of quickly reselling returns, those consumers who buy returned products may still return it if they find that the products cannot meet their expectations, implying that all returns would be eventually salvaged. In other words, only consumers who are really satisfied with the product will keep the product; thus, the seller bears all losses caused by uninformed purchases resulting from product misfit. From the seller's perspective, the two types of reselling policies are the same. Conversely, if returns are not allowed, all consumers make an uninformed purchase and undertake all losses caused by product misfit, which benefits the seller. Consequently, compared with not allowing returns, providing full refunds may not benefit the seller.

Next, we examine whether creating an offline showroom or artificial intelligence adoption is helpful in lessening or even eliminating the potential downside of the seller providing full refunds compared with not allowing returns.

\section{Creating an offline showroom}

Ideally, creating an offline showroom can be helpful for consumers to ascertain product fit prior to making a purchase. We make the following simplifying assumption. On visiting the showroom, a consumer can entirely determine the fit information and make an informed purchase. That is, those consumers who really like the product buy it and keep it; otherwise, they do not purchase it. This assumption is reasonable as follows: From a practical perspective, an offline showroom can provide auxiliary guidance regarding product purchase, such as experts allaying consumer's concerns about product fit gap. In the event of a poor match or even full mismatch, the consumer does not purchase the product. Considering this, a fraction $m$ of consumers who are satisfied with the product buy and keep it, which we label as the "demand lessening effect". From a theoretical perspective, Shulman et al. (2009), Balakrishnan et al. (2014), Gao and Su (2017), and Bell et al. (2018) all consider that after physically touching the product, trialing the product and receiving on-site consultation in the showroom, a consumer will not return the product after purchase.

Following convention (e.g., Ofek et al. 2011; Jing 2018), we assume that consumers are heterogeneous with respect to their cost $\beta$ of visiting showroom. Thus, let $G(\cdot)$ with support $[0, \bar{\beta}]$ denote the cumulative distribution of $\beta$ and $g(\cdot)$ denote its density, and $\bar{G}(\beta)=1-G(\beta)$. Each consumer needs to balance between visiting the showroom and purchasing online directly by comparing the expected surplus. First, she visits the showroom to inspect the product. If satisfied, she then switches to the online channel for purchase, yielding an expected surplus $\mu_{b}=m(v-p)-\beta$. More importantly, she does not return the product. Second, if choosing to buy online directly, she can get an expected surplus $\mu_{n}=m(v-p)-(1-m) t$, where $m(v-p)$ denotes the payoff of keeping the product, and $(1-m) t$ is the loss of returning it. According to $u_{n}=u_{b}$, we get $\beta_{R}=(1-m) t$, such that if offline visiting cost $\beta$ is less than $\beta_{R}$, the consumer prefers visiting the showroom, which we label "informed consumer"; when $\beta$ is greater than $\beta_{R}$, she tends to make an uninformed online purchase directly, which we label "uninformed consumer". 


\subsection{Salvaging returns}

Similarly, when all returns are resold at a salvage value (ER policy), the seller's expected profit can then be expressed as

$$
\begin{aligned}
\Pi_{E R}(q)= & p \int_{0}^{\frac{q}{\bar{G}\left(\beta_{R}\right)+m G\left(\beta_{R}\right)}}\left[\bar{G}\left(\beta_{R}\right)+m G\left(\beta_{R}\right)\right] x f(x) d x \\
& +p \int_{\overline{\bar{G}\left(\beta_{R}\right)+m G\left(\beta_{R}\right)}}^{\frac{q}{\bar{G}\left(\beta_{R}\right)}}\left[\bar{G}\left(\beta_{R}\right) x+\left(q-\bar{G}\left(\beta_{R}\right) x\right)\right] f(x) d x \\
& +p \int_{\frac{q}{\bar{G}\left(\beta_{R}\right)}}^{+\infty} q f(x) d x+s \int_{0}^{\overline{\bar{G}\left(\beta_{R}\right)+m G\left(\beta_{R}\right)}}\left\{q-\left[\bar{G}\left(\beta_{R}\right)+m G\left(\beta_{R}\right)\right] x\right\} f(x) d x \\
& -(p-s)(1-m) E \min \left[q, \bar{G}\left(\beta_{R}\right) x\right]-c q .
\end{aligned}
$$

In Eq. (5), $(1-m) E \min \left[q, \bar{G}\left(\beta_{R}\right) x\right]$ denotes the total number of returns, where the first item corresponds to the revenue when $x \leq q /\left[\bar{G}\left(\beta_{R}\right)+m G\left(\beta_{R}\right)\right]: \bar{G}\left(\beta_{S R}\right) x$ and $m G\left(\beta_{S R}\right) x$ represent the sales to uninformed and informed consumers, respectively. The second item represents the revenue when $q /\left[\bar{G}\left(\beta_{R}\right)+m G\left(\beta_{R}\right)\right]<x \leq q / \bar{G}\left(\beta_{R}\right)$, where $\bar{G}\left(\beta_{R}\right) x$ and $q-\bar{G}\left(\beta_{R}\right) x$ represent the sales to uninformed and informed consumers, respectively. The third item indicates the revenue when $x>q / \bar{G}\left(\beta_{S R}\right)$, and the seller only sells the products to uninformed consumers. The fourth item comes from salvaging new units. The fifth item represents the loss caused by returns. The last item is the procurement cost.

After calculation and arrangement, Eq. (5) becomes:

$$
\begin{aligned}
\Pi_{E R}(q)= & (p-s) E \min \left\{q,\left[\bar{G}\left(\beta_{R}\right)+m G\left(\beta_{R}\right)\right] x\right\}-(c-s) q \\
& -(p-s)(1-m) E \min \left[q, \bar{G}\left(\beta_{R}\right) x\right] .
\end{aligned}
$$

Solving this optimization problem, we have the following Proposition 3:

Proposition 3 (1) Under ER policy, the optimal quantity $q_{E R}^{*}$ should satisfy

$$
\frac{d \Pi_{E R}}{d q}=(p-s) \bar{F}\left[\frac{q}{\bar{G}\left(\beta_{R}\right)+m G\left(\beta_{R}\right)}\right]-(1-m)(p-s) \bar{F}\left[\frac{q}{\bar{G}\left(\beta_{R}\right)}\right]-(c-s)=0 .
$$

(2) The seller's optimal profit $\Pi_{E R}^{*}$ is increasing in both $t$ and $s$.

See the "Appendix B" for the proof.

The above results reveal that when the seller creates an offline showroom, (i) increasing consumer return costs (higher $\beta_{R}$ ) induces a higher proportion of consumers to fully ascertain product fit gap before purchase, thus lowering the loss caused by consumer returns. This argues that less uninformed consumers purchase online directly, which leads to a reduction in returns. Taken together, the seller gets an increase in optimal profit. In other words, the seller is better off increasing the return cost and discouraging returns (Akçay et al. 2013). As a consequence, the seller benefits from providing a showroom rather than looking for ways to reduce consumer return costs. (ii) Increasing the salvage value the seller can extract from leftovers, including returns, helps increase profits.

The following Proposition 4 compares optimal profit under $E R$ policy, $R$ policy, and benchmark policy. 
Proposition 4 The seller's optimal profit under ER policy is generally higher than under $R$ policy, but lower than that of not allowing returns, i.e., $\Pi_{R}^{*} \leq \Pi_{E R}^{*}<\Pi_{B}^{*}$.

See "Appendix B" for the proof.

According to Proposition 4, first, regardless of whether the seller adds an offline showroom, all leftovers, including returns, are salvaged in period $t_{2}$. Under $R$ policy, all consumers make an uninformed purchase, which leads to a higher number of returns. Moreover, under $E R$ policy, informed consumers buy products and keep them, which leads to a reduction in returns. These together, with a higher marginal loss of providing full refunds, increase the seller's optimal profit and be generally higher than $R$ policy. Second, by comparing Eq. (2) and Eq. (6), we show that providing full refunds exclusively ( $R$ policy) is a special setting of $E R$ policy when $\beta_{R}=0$, and all consumers make an uninformed online purchase directly. Furthermore, under $E R$ policy, we get that $\beta_{R} \geq 0$, and with the increase in consumer return costs (higher $\beta_{R}$ ), more consumers tend to visit the showroom first, which heavily reduces returns; hence, the seller's optimal profit under $E R$ policy is generally higher than that under $R$ policy. Though creating an offline showroom may result in fewer returns, it lessens the demand base because those consumers who visit the showroom and find a poor match or entire misfit do not make a purchase, implying that the optimal profit of the seller under $E R$ policy is lower than that of not allowing returns.

\subsection{Quick resale of returns}

When returns can be quickly resold in period $t_{1}$ ( $E Q$ policy), or if offline visiting cost $\beta$ is less than $\beta_{R}$, the consumer tends to make an informed purchase; otherwise, she makes an uninformed online purchase directly.

Next, we examine the seller's decision problem. First, when demand $x \leq q /\left[\bar{G}\left(\beta_{R}\right)+\right.$ $\left.m G\left(\beta_{R}\right)\right]$, sales to informed and uninformed consumers are $m G\left(\beta_{S R}\right) x$ and $\bar{G}\left(\beta_{S R}\right) x$, respectively. In this respect, even though returns are recovered quickly and resold in period $t_{1}$, because demand is less than the stocking quantity, no consumers need to purchase returns; thus, all returns are salvaged eventually in period $t_{2}$. Second, when $q /\left[\bar{G}\left(\beta_{R}\right)+m G\left(\beta_{R}\right)\right]<x \leq q / \bar{G}\left(\beta_{R}\right)$, the number of new products sold to uninformed consumers is $\bar{G}\left(\beta_{R}\right) x$, then the number of products available for sale to informed consumers is $S_{0}=q-\bar{G}\left(\beta_{R}\right) x+(1-m) \bar{G}\left(\beta_{R}\right) x$, where $q-\bar{G}\left(\beta_{R}\right) x$ denotes the number of new products that can be sold to informed consumers, and $(1-m) \bar{G}\left(\beta_{R}\right) x$ units are bought but returned by uninformed consumers, while the demand of informed consumers is $D_{0}=m G\left(\beta_{S R}\right) x$. Comparing $S_{0}$ and $D_{0}$, if $x \leq q / m$, then $S_{0} \geq D_{0}$, the sales to informed consumers are $D_{0}$, and the number of products that need to be salvaged is $q-m x$; if $x>q / m$, then $S_{0}<D_{0}$, the sales to informed consumers become $S_{0}$, and these products are not returned. Third, when $x>q / \bar{G}\left(\beta_{R}\right)$, the number of new products sold to uninformed consumers is $q$, the number of returns is $S_{10}=(1-m) q$, while the remaining demand of uninformed consumers is $D_{n 0}=\bar{G}\left(\beta_{R}\right) x-q$. Comparing $S_{10}$ and $D_{n 0}$, (i) if $x<[1+(1-m)] q / \bar{G}\left(\beta_{R}\right)$, then $S_{10}>D_{n 0}$, the number of new products sold to remaining uninformed consumers is $D_{n 0}$, the number of returns becomes $(1-m) D_{n 0}$, and the sales to informed consumers become $S_{10}-D_{n 0}$; likewise, these products are not returned. Because all uninformed consumers have purchased products and are only allowed to return them once, these returns $(1-m) D_{n 0}$ are finally resold to informed consumers. (ii) If $x \geq[1+(1-m)] q / \bar{G}\left(\beta_{R}\right)$, we have that $S_{10} \leq D_{n 0}$, the sales to remaining uninformed consumers become $S_{10}$, and the number of returns becomes $S_{11}=(1-m) S_{10}$, which are also available for sale. Meanwhile, demand of uninformed consumers who have not purchased the product becomes 
$D_{n 1}=D_{n 0}-S_{10}$. Following the same logic as above, if $x<\left[1+(1-m)+(1-m)^{2}\right] q / \bar{G}\left(\beta_{R}\right)$, then $S_{11}>D_{n 1}$, the number sold to the remaining uninformed consumers is $D_{n 1}$, and the sales to informed consumers become $S_{11}-D_{n 1}$. Likewise, the remaining uninformed consumers no longer purchase products and these returns are eventually resold to informed consumers; if $x \geq\left[1+(1-m)+(1-m)^{2}\right] q / \bar{G}\left(\beta_{R}\right)$, we have that $S_{11} \leq D_{n 1}$, the number sold to the remaining uninformed consumers is $S_{11}$, and the number of returns is $(1-m) S_{11}$. The rest may be deduced by analogy, and all returns $(1-m) q$ are eventually resold to informed consumers. More importantly, these consumers will not return the products.

Considering this discussion, if demand is less than the initial inventory, even though the seller is capable of reselling returns quickly, these returns will finally be salvaged (see case (1)). Conversely, if demand is greater than the stocking quantity (in case of a shortage), and the seller decides to resell returns quickly, these returns are essentially resold to informed consumers in period $t_{1}$ (see case (2) and case (3)). Hence, the seller's optimization problem involves maximizing

$$
\begin{aligned}
& \Pi_{E Q}(q) \\
& =\int_{0}^{\bar{G}\left(\beta_{R}\right)+m G\left(\beta_{R}\right)}\left\{p\left[\bar{G}\left(\beta_{R}\right)+m G\left(\beta_{R}\right)\right] x-(p-s)(1-m) \bar{G}\left(\beta_{R}\right) x+s\left[q-\left(\bar{G}\left(\beta_{R}\right)+m G\left(\beta_{R}\right)\right) x\right]\right\} d F(x) \\
& \quad+\int_{\overline{\bar{G}\left(\beta_{R}\right)+m G\left(\beta_{R}\right)}}^{\frac{q}{\bar{G}\left(\beta_{R}\right)}}\left[p \bar{G}\left(\beta_{R}\right) x-p(1-m) \bar{G}\left(\beta_{R}\right) x\right] d F(x)+\int_{\overline{\bar{G}\left(\beta_{R}\right)+m G\left(\beta_{R}\right)}}^{\frac{q}{m}}[\underbrace{m G\left(\beta_{R}\right) x}_{D_{0}}+s \underbrace{(q-m x)] d F(x)}_{S_{0}-D_{0}} \\
& \quad+\int_{\frac{q}{m}}^{\overline{\bar{G}\left(\beta_{R}\right)}} p[\underbrace{q-m \bar{G}\left(\beta_{R}\right) x}_{S_{0}}] d F(x)+\int_{\frac{q}{\bar{G}\left(\beta_{R}\right)}}^{+\infty}[p q+p(1-m) q] d F(x)-p \int_{\frac{q}{G\left(\beta_{R}\right)}}^{+\infty}(1-m) q d F(x)-c q .
\end{aligned}
$$

After calculation and arrangement, Eq. (8) becomes:

$$
\Pi_{E Q}(q)=(p-s) E \min (m x, q)-(c-s) q .
$$

Solving this optimization problem, we have the optimal quantity $q_{E Q}^{*}=m \bar{F}^{-1}[(c-$ $s) /(p-s)]$, and the resulting optimal profit $\Pi_{E Q}^{*}=m(p-s) \int_{0}^{\bar{F}^{-1}\left(\frac{c-s}{p-s}\right)} x f(x) d x$.

Proposition 5 Under $E Q$ policy, the optimal initial quantity $q_{E Q}^{*}$, and the resulting optimal profit $\Pi_{E Q}^{*}$ are a linear increasing in the product fit probability $m$, and do not depend on consumer return cost $t$.

See "Appendix B" for the proof.

Proposition 5 shows that, (1) when a seller creates an offline showroom, those consumers visiting the showroom make an informed purchase; therefore, the actual number of informed consumers making purchases becomes $m G\left(\beta_{R}\right) x$, while uninformed consumers purchase online directly and choose to return products in case of misfit. More importantly, only when new products are out of stock can these returns be resold to informed consumers who do not return the in period $t_{1}$, leading to the total number $m x$ of consumers keeping products. Furthermore, increasing fit probability $m$ increases the number of consumers keeping products, which results in an increase in the quantity and optimal profit. (2) The optimal quantity and profit do not depend on consumer return costs, which can be interpreted as follows: by comparing Eq. (6) and Eq. (9), we show that $E Q$ policy is the special case of $E R$ policy when $\beta_{R}=\bar{\beta}$, and all consumers $m x$ make informed purchases. Furthermore, under $E R$ policy, then $\beta_{R} \leq \bar{\beta}$. Not all consumers make informed purchases; that is, a proportion of consumers still make uninformed purchases and possibly return products, which, together with a higher 
marginal loss of the seller offering full refunds, leads to a lower optimal profit compared with $E Q$ policy. These results argue that the maximum value of a showroom is extracted through supplementing the offline showroom with the quick resale of returns. More interestingly, lowering consumer return costs to encourage purchases or increasing consumer return costs to discourage returns may not affect the seller's profits.

In Proposition 6 below, we compare $E Q$ policy, $R$ policy and a policy of not allowing returns in terms of stocking quantity and optimal profit.

Proposition 6 (1) Given $f^{\prime}(x) \geq 0$, let $s^{E Q}$ be the unique solution to $F^{-1}\left(\frac{p-c}{p-s}\right) f\left[F^{-1}\left(\frac{p-c}{p-s}\right)\right]=\frac{c-s}{p-s}$. If $s \leq s^{E Q}$, then $q_{E Q}^{*} \geq q_{R}^{*}$; if $s \geq s^{E Q}$, there exists a threshold $m^{*}$ such that when $m \leq m^{*}$, then $q_{E Q}^{*} \geq q_{R}^{*}$; when $m>m^{*}$, then $q_{E Q}^{*}<q_{R}^{*}$.

(2) The seller's optimal profit under $E Q$ policy is generally higher than under $R$ policy, but lower than not allowing returns, i.e., $\Pi_{R}^{*} \leq \Pi_{E Q}^{*}<\Pi_{B}^{*}$.

See "Appendix B" for the proof.

The condition $f^{\prime}(x) \geq 0$ in Proposition 6 is sufficient but not necessary. The increasing density condition holds, for example, in the case of a power distribution with an order greater than or equal to one.

Three cases are discussed in Proposition 6. First, if a salvage value $s$ that the seller can charge is less than $s^{E Q}$, the inventory quantity under $E Q$ policy is higher than the $R$ policy. This can be interpreted as follows: for $R$ policy, all consumers make an uninformed purchase, which leads to a larger number of returns, combined with a low salvage value leading to a low inventory; under $E Q$ policy, informed consumers keep products after purchase, which indirectly lowers returns. However, a fraction of returns from uninformed purchases can be resold to informed consumers, which further lessens the remaining returns that need to be salvaged in period $t_{2}$ and indirectly decreases the risk of excess inventory, thus leading to an inventory quantity higher than that which occurs in the $R$ policy. Second, if a salvage value $s$ is greater than $s^{E Q}$, whether the inventory quantity under $E Q$ policy is higher than that of the $R$ policy depends on the product fit probability $m$. Specifically, when $m$ is less than $m^{*}$, consumers are heavily unsure about fit; under $E Q$ policy, visiting offline an showroom becomes more attractive for consumers, thus more consumers make informed purchases. This indirectly reduces returns, which combined with a higher salvage value results in a higher inventory quantity compared with the $R$ policy. However, when $m$ is higher than $m^{*}$, consumers more reliably determine fit uncertainty; hence, visiting offline an showroom becomes less attractive. In this respect, more consumers make uninformed online purchases directly, yet a higher product match probability directly reduces returns; thus, the inventory quantity under $E Q$ policy is lower than that of the $R$ policy.

Finally, the seller's optimal profit under $E Q$ policy is higher than that of the $R$ policy, and this is explained by comparing the proportion of uninformed and informed consumers between $R$ policy and $E Q$ policy. $R$ policy is the special case of $E R$ policy when $\beta_{R}=0$, and all consumers make uninformed purchases; $E Q$ policy is the special case of $E R$ policy when $\beta_{R}=\bar{\beta}$, and all consumers make informed purchases. Under $E Q$ policy, then $\beta_{R} \in[0, \bar{\beta}]$. This implies that a proportion of consumers is uninformed, and the remaining consumers become informed purchasers. As mentioned in Proposition 5, increasing consumer return costs (higher $\beta_{R}$ ) converts more uninformed consumers into informed consumers, which greatly reduces returns. Hence, the seller benefits from an offline showroom instead of providing full refunds only. Furthermore, compared with not allowing returns, though creating an offline showroom may result in no loss due to returns because fit uncertainty is fully solved, it decreases demand 
base because those consumers who visit the showroom and find a poor match or entire misfit do not make purchases. Therefore, the optimal profit under $E Q$ policy is lower than that of not allowing returns.

\section{Artificial intelligence adoption}

In this section we analyze how adopting artificial intelligence that effectively lowers product fit uncertainty and objectively recommends better matching exchanges affects the returns policies when the seller provides full refunds for returns.

\subsection{Artificial intelligence eliminates fit uncertainty}

First, we consider the ideal setting in which the application of artificial intelligence entirely eliminates product fit uncertainty. In other words, on obtaining the artificial intelligence personalized virtual-reality experience, the consumer discovers and learns fit information completely, then makes an informed purchase. Hence, the actual number of consumers who make purchases and keep the products is $m x$. Considering this, artificial intelligence adoption and creation of an offline showroom are equal in eliminating product fit uncertainty. The seller's expected profit can be shown as

$$
\Pi_{A}(q)=p E \min (m x, q)+s[q-E \min (m x, q)]-c q .
$$

In Eq. (10), the first item corresponds to the revenue from the products kept, the second item captures revenues from salvaging the new products, and the last item is the procurement cost.

Solving this optimization problem allows us to have the optimal quantity $q_{A}^{*}=m \bar{F}^{-1}[(c-$ $s) /(p-s)]$, and the resulting optimal profit $\Pi_{A}^{*}=m(p-s) \int_{0}^{\bar{F}^{-1}[(c-s) /(p-s)]} x f(x) d x$.

Lemma 1 If artificial intelligence adoption entirely eliminates product fit uncertainty, the optimal quantity $q_{A}^{*}$ and optimal profit $\Pi_{A}^{*}$ are a linear increase in the product fit probability $m$.

Lemma 1 shows that as the probability $m$ of a consumer really liking the product increases, the number of consumers keeping products increases, thus increasing the quantity and optimal profit.

Proposition 7 Suppose that artificial intelligence adoption fully eliminates fit uncertainty. Compared with creating an offline showroom, artificial intelligence adoption better benefits the seller, i.e., $\Pi_{E R}^{*} \leq \Pi_{E Q}^{*}=\Pi_{A}^{*}$. However, the seller prefers not allowing returns to offering an artificial intelligence experience, i.e., $\Pi_{A}^{*}<\Pi_{B}^{*}$.

Proposition 7 highlights that the optimal profit of a seller adopting artificial intelligence technologies is not less than creating an offline showroom. Specifically, by comparing Propositions 3 and 7, we find that employing artificial intelligence may benefit the seller more than creating an offline showroom when all returns are eventually salvaged. This is because the former induces all consumers to make an informed purchase while the latter only encourages a fraction of consumers to make an informed purchase. Furthermore, adopting artificial intelligence while salvaging returns provides sellers with profits equal to those provided by creating an offline showroom and reselling returns quickly. However, compared with not 
allowing returns, the adoption of artificial intelligence leads to a lower profit for the seller. This follows from when returns are not allowed, even though consumers make uninformed purchases, they do not return them in the case of misfit. This means that all consumers make an "implicit" informed purchase, greatly increasing the seller's profits. However, as mentioned before, adopting artificial intelligence lessens the demand base and the resulting profit. Hence, the artificial intelligence experience still leads to a lower profit for the seller compared with not allowing returns.

\subsection{Artificial intelligence lowers fit uncertainty}

More practically, products such as apparel comprise a digital attribute and a nondigital attribute; thus, adopting artificial intelligence technologies (virtual fitting-room technologies, chatbots, intelligent recommending agents) may (i) greatly lower the search cost and product fit gap of consumers through accurate analysis of their preferences, and (ii) expand the demand base by converting more browsers into purchasers and recommending products to other potential consumers who need but do not know assistance from artificial intelligence technologies. For example, virtual fitting technologies developed by the online seller HAOMAIYI may help increase purchasers by $12.4 \%$, and reduce the return rate of some brands by about 30\% (You 2017). In addition, Gallino and Moreno (2018) reported that virtual fitting-room technologies result in an approximately $71.8 \%$ of total incremental benefit from browsers into purchasers, and $16.6 \%$ from lower returns.

To clarify our results, we make the following simplifying assumption. First, the probability of return $(1-m)$ falls to $(1-m)(1-\lambda)$ once a consumer gets personalized artificial intelligence experience $(0 \leq \lambda \leq 1)$, where $\lambda$ captures the level of product fit uncertainty reduced by the artificial intelligence experience. Second, we denote the expanding (or lessening) demand base by using $\theta(\lambda) x$, where $\theta(\lambda)>1$ represents that implementing artificial intelligence expands the demand base by accurately recommending products to browsers and other potential consumers. Intuitively, this demand expanding effect is also explained as the artificial intelligence personalized experience increasing consumers' attachment to the product. In addition, Kim and Krishnan (2015) report that providing more fit information induces higher sales. Conversely, $\theta(\lambda)<1$ captures a setting where the artificial intelligence experience may be perceived as less knowledgeable and less empathetic by consumers, as in Luo et al. (2019). Intuitively, the artificial intelligence experience should not diminish the demand base, thus we assume that $d \theta(\lambda) / d \lambda=\theta^{\prime}(\lambda) \geq 0$. All returns are salvaged eventually in period $t_{2}$. The seller's expected profit can be expressed as

$$
\begin{aligned}
\Pi_{P}(q)= & p[1-(1-m)(1-\lambda)] E \min [\theta(\lambda) x, q]+s(1-m)(1-\lambda) E \min [\theta(\lambda) x, q] . \\
& +s[q-E \min (\theta(\lambda) x, q)]-c q
\end{aligned} .
$$

In Eq. (11), the first item corresponds to the revenue from the products kept, the second item indicates the loss from consumer returns, the third item captures revenues from salvaging new products, and the last item is the procurement cost.

Solving the optimization problem allows us to get the optimal quantity as follows:

$$
q_{P}^{*}=\theta(\lambda) \bar{F}^{-1}\left[\frac{c-s}{p-s} \frac{1}{m+(1-m) \lambda}\right] .
$$

The optimal profit is given by $\Pi_{P}^{*}=(p-s)[m+(1-m) \lambda] \theta(\lambda) \int_{0}^{\bar{F}^{-1}\left[\frac{c-s}{p-s} \frac{1}{m+(1-m) \lambda}\right]} x f(x) d x$. 
Proposition 8 Suppose that providing an artificial intelligence personalized experience stimulates the demand base and lessens fit uncertainty. Then, there exists two thresholds, $\lambda_{1}$ and $\lambda_{2}\left(\lambda_{1}<\lambda_{2}\right)$ such that when $\lambda \leq \lambda_{1}$, then $\Pi_{P}^{*} \leq \Pi_{E Q}^{*} \leq \Pi_{B}^{*}$; when $\lambda \in\left(\lambda_{1}, \lambda_{2}\right]$, then $\Pi_{E Q}^{*}<\Pi_{P}^{*} \leq \Pi_{B}^{*}$; when $\lambda>\lambda_{2}$, then $\Pi_{E Q}^{*} \leq \Pi_{B}^{*}<\Pi_{P}^{*}$.

\section{See "Appendix B" for the proof.}

Proposition 8 proves an interesting and strong connection between the artificial intelligence experience and offering full refund. Theoretically, when the additional fit information that artificial intelligence adoption provides is available, potential browsers are more likely to become purchasers, and purchasers are less likely to return purchased products.

First, compared with not allowing returns, if the level of lowering fit uncertainty by artificial intelligence adoption is less than threshold $\lambda_{2}\left(\lambda \leq \lambda_{2}\right)$, it is not conducive for consumers to ascertain fit information, which not only leads to a large number of returns and resulting losses, but also is not conducive to the conversion of browsers into purchasers. In this respect, the seller should not provide an artificial intelligence personalized experience. However, if the level of lowering fit uncertainty is generally high $\left(\lambda>\lambda_{2}\right)$, it is more helpful for consumers when they ascertain product fit. Thus, an artificial intelligence personalized experience not only leads to a substantial reduction in returns and resulting losses, but converts more browsers or even other potential uninformed consumers into actual purchasers. Considering this discussion, the seller is better off providing an artificial intelligence experience when offering full refunds.

Second, compared with creating an offline showroom instead of not allowing returns, implementing artificial intelligence expands the range of parameter $\lambda$. In other words, even though $\lambda$ is less than $\lambda_{2}$, as long as it is greater than $\lambda_{1}$, i.e., $\lambda \in\left[\lambda_{1}, \lambda_{2}\right)$, adopting artificial intelligence still benefits the seller more than creating an offline showroom. This is because the latter reduces the fraction of consumers buying products, which reduces the optimal profit. Therefore, when $\lambda$ is above $\lambda_{1}$, the increased revenue from both expanding the demand base and reducing returns sufficiently compensates for the loss of the remaining returns, which makes the seller's total profit higher than when providing an offline showroom; by contrast, if $\lambda$ is below $\lambda_{1}$, regarding providing an artificial intelligence experience, the increased revenue from the above two aspects does not compensate for the loss of the remaining returns, indicating that the seller should provide an offline showroom rather than implement artificial intelligence.

\subsection{Artificial intelligence recommends better-matching exchanges}

In this section, we examine what exchange products the adopted artificial intelligence should accurately and objectively recommend to consumers who hope to make a full refund claim in the case of returns. In other words, we focus on whether the artificial intelligence that the seller employs deeply analyzes the reason for returns and accurately recommends better-matching alternatives effectively enhances the value of after-sales services (i.e., the return experience). To a certain extent, providing full refunds is helpful for consumers to search and ascertain the best fit information. Ertekin (2018) provides evidence that the offline return experience influences consumer exchange and repurchase behavior through salesperson competence and selling pressure. More crucially, selling pressure may come from a fraction of the commission depending heavily on sales performance. Unlike the traditional offline experience, Luo et al. (2019) show that online artificial intelligence chatbots are as effective as salespeople in terms of competence but do not have the selling pressure of salespeople. Taken together, the 
artificial intelligence return experience helps consumers learn the true reason for the misfit of the initial purchase, find a better-matching exchange and eventually keep it.

In broad terms, an exchange (alternative) recommended by artificial intelligence can be partitioned into horizontally and vertically differentiated products. Compared with the product initially sold, a horizontally differentiated exchange has similar characteristics but with better-matching information, which can be explained as the replacement of the same subcategory. A vertically differentiated exchange has not only a higher quality but also bettermatching information, which can be regarded as a cross-category replacement. Shulman et al. (2009) consider horizontally differentiated exchanges that better fit consumers' expectations but has the same net profit margin $p-c$ as the initial products, but Samorani et al. (2019) focus on vertically differentiated exchange, reporting that if a consumer initially purchases a JVC for US\$159.99, then replaces it during the exchange with an SON for US\$229.98, the consumer eventually keeps it. We assume that upon returning products, a fraction $\rho \in[0,1]$ of consumers buy the recommended exchange, and the remaining consumers choose to make a full refund claim. For simplicity, we also assume that an exchange is modeled exogenously. For each exchange or repurchase product, the seller obtains a net profit margin $w$. Hence, the seller's profit can be expressed as

$$
\begin{aligned}
\Pi_{A R}(q)= & p m E \min (q, x)+s(1-\rho)(1-m) E \min (q, x) \\
& +\rho(s+w)(1-m) E \min (q, x)+s[q-E \min (q, x)]-c q .
\end{aligned}
$$

In Eq. (13), the first item corresponds to the revenue from the products kept, the second item indicates the loss from returns, the third item captures revenues from exchanges, the fourth item captures revenues from salvaging the new products, and the last item is the procurement cost.

Solving this optimization problem allows us to get $q_{A R}^{*}=\bar{F}^{-1}\left[\frac{c-s}{(p-s) m+\rho w(1-m)}\right]$, and $\Pi_{A R}^{*}=[(p-s) m+\rho w(1-m)] \int_{0}^{q_{A R}^{*}} x f(x) d x$.

Lemma 2 Supposing that artificial intelligence objectively recommends better-matching exchanges, the optimal profit $\Pi_{A R}^{*}$ is a convex increase in $w$.

Lemma 2 reveals that as the net profit margin $w$ of exchanges increases, the seller can keep some or all of the profit margin from the initial sales, which results in an increase in optimal profits.

Proposition 9 When artificial intelligence can objectively recommend better-matching exchanges, (i) there exists a threshold $w^{*} \in(0,(p-s) / \rho)$ such that if $w \leq w^{*}$, then $\Pi_{A R}^{*} \leq \Pi_{E Q}^{*}<\Pi_{B}^{*}$; if $w \in\left(w^{*},(p-s) / \rho\right]$, then $\Pi_{E Q}^{*}<\Pi_{A R}^{*}<\Pi_{B}^{*}$; if $w>(p-s) / \rho$, then $\Pi_{A R}^{*}>\Pi_{B}^{*}>\Pi_{E Q}^{*}$. (ii) $\Pi_{A R}^{*}>\Pi_{R}^{*}$.

Proposition 9 highlights how the application of artificial intelligence affects the seller's profits.

(i) Comparison between employing artificial intelligence and not allowing returns.

Compared with not allowing returns, if the net marginal profit of an exchange recommended by artificial intelligence is sufficiently high $(w>(p-s) / \rho)$, such as a vertically differentiated product with a relatively high marginal profit, it helps to increase the profits of the seller by facilitating consumers' continuous searches. Considering this discussion, returns should not be deemed as cost centers to be minimized but rather as opportunities to extract value from returned products. Additionally, sometimes some consumers may delay an exchange and 
buy another product a few days later (Samorani et al. 2019). Moreover, if a recommended exchange has a low marginal profit $(w \leq(p-s) / \rho)$, even though allowing returns provides for the consumer's continuous search, it may not benefit the seller because salvaging returns seriously erodes the profit margin of initial sales. This, together with a lower profit margin of an exchange, results in a reduction in revenues. Taken together, the seller should minimize returns. For example, the marginal profit of a horizontally differentiated exchange is $p-c$, as in Shulman et al. (2009), which is far below $(p-s) / \rho$, making the profit of the seller lower than not allowing returns. This follows from the seller's revenue from the sales of exchanges needing to compensate for the full refunds of the fraction of consumers returning products. Conversely, when returns are not allowed, the seller does not need to compensate consumer loss caused by product mismatch. Taking these two aspects into account, application of artificial intelligence may not benefit the seller more than not allowing returns.

(ii) Comparison between artificial intelligence application and creating offline showroom.

Now that the threshold $w^{*}$ is less than $(p-s) / \rho$, adopting artificial intelligence expands the range of parameter $w$. Further, if $w \in\left(w^{*},(p-s) / \rho\right]$, adopting artificial intelligence is still more beneficial to the seller than creating an offline showroom. This is because the latter reduces the fraction of consumers buying products, leading to a reduction in the seller's profits. Therefore, as long as $w$ is greater than $w^{*}$, the increased revenue from exchanges compensates sufficiently for the loss of salvaging returns, which leads to an increase in the seller's profits to a point that is higher than that from providing an offline showroom.

Combining all the above discussions, though sometimes implementing artificial intelligence cannot significantly eliminate returns, it still provides after-sales service (return) experiences, which is also conducive to sellers because accurately recommending exchanges for returns is helpful for consumers who seek a better-matching exchange continuously, and also helps to increase the profits of the seller.

\subsection{Case analysis of Stitch Fix}

In this section we analyze how Stitch Fix adopted artificial intelligence to decrease consumer returns as well as increase its profitability.

First, Stitch Fix's artificial intelligence, which uses massive data and algorithms, can accurately recommend matching apparel products. Broadly, there are two competitive strategies in online business: focusing on low prices and fast shipping, such as Amazon.com, Taobao.com, and JD.com, and focusing on creating a significantly superior personalized service experience, such as Stitch Fix. With the emergence of new retail operations, increasingly more consumers pay greater attention to the personalized service experience. Stitch Fix meets this experience by accumulating massive amounts of data and adopting artificial intelligence. According to a 2016 Internet trend report, if Stitch Fix's artificial intelligence predicts that consumers have a $100 \%$ probability of purchasing some kind of clothing, the actual probability of consumers' purchases is as high as 90\% (Meeker 2016). This shows that adoption of artificial intelligence greatly lowers the product fit uncertainty and helps the vast majority of consumers make an informed purchase, thus heavily lessening the number of returns.

Second, the consumer incurs the return cost. A consumer needs to pay a US\$20 styling fee up front, then Stitch Fix mails a box containing five clothing items personalized to her within the agreed period. If the consumer does not like them, she may return them to make a full refund claim, but incurs the return cost of US\$20, specifically, the US\$20 styling fee she paid in advance is converted into the return cost (Lake 2018). More realistically, many 
consumers tend to avoid the trouble of the return and keep the items, which further lowers returns to a certain extent.

Third, the profit margin of clothing sold by Stitch Fix is high. Stitch Fix's profit margin rate increased from $35.2 \%$ in 2014 to $44.5 \%$ in 2017 (Zhen 2017). Consequently, a relatively high profit margin not only is helpful for Stitch Fix to heavily invest in personalized service innovation, but rather helps to compensate for the loss caused by salvaging consumer returns. In addition, Gallino and Moreno (2018) estimate that the cost of apparel products sold by Metail, which offers virtual fitting-room technologies, only accounts for $30 \%$ of the revenue. This also shows that a high marginal profit can hedge against the loss caused by salvaging remaining returns. Essentially, the high profit margin of clothing sales is the core driver of artificial intelligence adoption.

Finally, the repurchase rate of consumers is very high. According to statistics, in 2016 and 2017, the repurchase rate of Stitch Fix's consumers was $83 \%$ and $86 \%$, respectively (Zhen 2017). This shows that the adoption of artificial intelligence by Stitch Fix significantly enhances the personalized service experience of after-sales, and accurately recommends better-matching exchanges as well as subsequent repurchase products to consumers, which help to increase its long-term benefits and sustainable profitability.

Considering this discussion, artificial intelligence adoption is helpful for consumers to make an informed purchases, and for Stitch Fix to recommend better-matching apparel products.

\section{Managerial implications of artificial intelligence adoption}

\subsection{Implications for practice}

First, artificial intelligence adoption that accurately recommends vertically differentiated exchanges with a relatively high marginal profit may be helpful for sellers to increase profits when consumers return initial product. Consequently, returns might be deemed as opportunities to facilitate consumers' continuous searches of exchanges.

Second, theoretically, artificial intelligence adoption that accurately profiles consumer browsing and purchasing data and preferences by using data insight technologies may effectively lessen or even eliminate product fit uncertainty, which is helpful for sellers to segment consumers, maximizing extraction of consumer surplus. However, with the continuous fermentation of big data killing events, increasingly more consumers immediately delete browsing and purchasing records after purchasing products, which is not good for artificial intelligence that accurately profiles consumer intrinsic preferences. Therefore, we caution that the seller must carefully consider the fairness of each consumer's purchase caused by continuous fermentation of big data killing events when adopting artificial intelligence technologies and agents.

Third, when a seller introduces a new product, consumers face extreme product fit uncertainty. In this case, two types of operational innovation can be adopted. It is also worth noting, however, that the return cost is becoming an important factor influencing whether consumers buy products online. More specifically, if the return cost turns out to be relatively low, consumers prefer to make uninformed purchases directly, resulting in a larger number of returns. In this respect, the seller is better off adopting artificial intelligence to enhance the personalized virtual-reality experience through which returns are greatly decreased. If the consumer returns cost is high, conventional wisdom holds that the seller should lower 
the consumer returns costs by permitting in store returns for online purchases, or allowing consumers to purchase return freight insurance to reduce the cost of returns. We caution that lowering consumer returns costs prompts more consumers to make uninformed purchases directly, which leads to an increasing number of returns. A more effective measure for the seller is to provide an artificial intelligence virtual-reality experience, encouraging consumers to make informed purchases. As the product lifecycle progresses, consumers get more information regarding the product fit gap and tend to make a more informed purchases directly, which lowers the value of the service experience. Correspondingly, both offline showrooms and artificial intelligence technologies extract a lower value of the service experience.

Last, from the perspective of operational innovation, creating an offline showroom may focus heavily on avoiding a fraction of returns, but possibly lessen the actual demand base; however, artificial intelligence adoption may balance reducing the probability of returns and expanding the demand base. More importantly, adopting artificial intelligence in a new retail operation deeply enhances the personalized service experience, which creates stickiness of consumers. Consequently, supplementing artificial intelligence adoption with a policy of allowing returns may benefit sellers even though consumers sometimes abuse the returns policies. This is reflected in helping the seller achieve two transformations, including (i) from exclusively selling products and services to entirely managing consumers' personalized lifestyles; and (ii) from the initial profit center to the novel retail infrastructure service provider based on the value and experience center.

\subsection{Implications for research}

First, the implication for research of our study was to combine three existing areas: (i) online returns policies, (ii) creation of offline showrooms, and (iii) application of artificial intelligence technologies. By incorporating the above areas, we hopefully are better able to provide a new vision for interdisciplinary integration. Second, existing studies mainly empirically and experimentally examine how artificial intelligence adoption affects online returns policies whereas our research complements this literature by analytically incorporating reselling returns as well as demand uncertainty, and specifically analyzing the case of Stitch Fix to further reveal how artificial intelligence effectively deals with online returns under a new retail operation. Finally, we use an analytic modeling method to compare two types of operational innovation: offline showrooms focusing on the physical experience and artificial intelligence adoption focusing on a personalized virtual experience.

\section{Conclusions}

The lack of touch-and-feel experience for online purchases increases product fit uncertainty, which reduces the purchase initiative of consumers. The implied "insurance" mechanism of the seller providing full (or nearly full) refunds induces more consumers to buy products. However, how to resell returns that do not have defects has become the most apparent side effect of sellers' operations. Therefore, it is crucial for practitioners and academics to ascertain how online sellers can balance minimizing returns and allowing returns. Motivated by practice of online business, this paper focused on exploring two types of operational 
innovation: offline showrooms and artificial intelligence adoption. Creating offline showrooms may help consumers have opportunities to touch and try products, thus increasing their acceptances of the products. However, the adoption of artificial intelligence may lower product fit uncertainty and improve after-sales services. Furthermore, the previous empirical and experimental studies regarding both operational innovations provide little information regarding reselling returns and demand uncertainty, but both have a profound impact on online operations. Considering this discussion, this paper focused on examining whether artificial intelligence adoption is more beneficial to sellers than offline showrooms or even not allowing returns, and how these affect consumers' purchase decisions as well as sellers' returns policies.

We obtained the following valuable results. First, artificial intelligence adoption is better for accurately recommending vertically differentiated exchanges with a relatively high marginal profit. Second, compared with the seller's most desired no returns policy, whether artificial intelligence adoption substantially benefits the seller depends on how much it lessens misfit and expands the demand base with initial sales. Third, compared with creating offline showrooms, artificial intelligence adoption expands the range of the level of lessening misfit and the net profit margin of exchange recommended. Last, we caution that the seller must rationally consider the fairness of consumers' purchases caused by continuous fermentation of big data killing events when adopting artificial intelligence to accurately profile consumers' preferences.

This analysis can be extended in several directions. First, our research mainly focuses on the impact of artificial intelligence adoption on online returns policies, with the rise of the new retail mode, more online sellers need to integrate online and offline channel operations to provide a seamless consumer experience; hence, research on how artificial intelligence affects omnichannel returns policies can further extract value from artificial intelligence. Second, this paper studied how consumer returns are driven by product fit uncertainty. However, in practice, even though the product sometimes does meet a consumer's expectation, she still returns it and makes an illegitimate claim intentionally, which can be regarded as abusing the returns policy. Thus, evaluating the effect of artificial intelligence adoption on abuse of the returns policy is an interesting avenue of future research. Finally, we focused on how artificial intelligence objectively recommends better-matching exchanges, but as mentioned before, big data killing events make increasingly more consumers reluctant to buy products (exchanges) recommended by artificial intelligence. Consequently, studying the game between sellers who desire to profile more accurate consumer preferences by adopting artificial intelligence and consumers who avoid artificial intelligence monitoring as much as possible can better reveal the applicability of artificial intelligence technologies.

Acknowledgements The authors thank the editors and two referees for their helpful suggestions and comments during the review process. This research is supported by the Natural Science Foundation of China (Grant Numbers 71872158,71871197 and 71571151).

Open Access This article is licensed under a Creative Commons Attribution 4.0 International License, which permits use, sharing, adaptation, distribution and reproduction in any medium or format, as long as you give appropriate credit to the original author(s) and the source, provide a link to the Creative Commons licence, and indicate if changes were made. The images or other third party material in this article are included in the article's Creative Commons licence, unless indicated otherwise in a credit line to the material. If material is not included in the article's Creative Commons licence and your intended use is not permitted by statutory regulation or exceeds the permitted use, you will need to obtain permission directly from the copyright holder. To view a copy of this licence, visit http://creativecommons.org/licenses/by/4.0/. 


\section{Appendix A: Notation}

Variable notation

$x$ : The total demand

$p, s:$ Sales price (salvage value)

$m$ : Product fit probability

$t, \beta$ : Consumer return costs (offline visiting cost)

$v$ : Consumer value with product fit

$\lambda$ : The level of AI lowering fit uncertainty

$\rho$ : Fraction of consumers buying exchanges

$w$ : Net profit margin of an exchange

$q, \Pi$ : The stocking quantity (the profit of seller)

\section{Appendix B: Proofs}

Proof of Proposition 1 To make $q_{B}^{*} \geq 0$ holds, condition $m \geq \underline{m}=(c-s) /(p-s)$ must be satisfied.

$$
\frac{d q_{B}^{*}}{d m}=\frac{1}{f\left(q_{B}^{*}\right)} \frac{c-s}{m^{2}(p-s)}>0 ; \quad \frac{d^{2} q_{B}^{*}}{d m^{2}}=-\frac{f^{\prime}\left(q_{B}^{*}\right)}{\left[f\left(q_{B}^{*}\right)\right]^{2}} \frac{d q_{B}^{*}}{d m} \frac{c-s}{m^{2}(p-s)}-\frac{1}{f\left(q_{B}^{*}\right)} \frac{2(c-s)}{m^{3}(p-s)} .
$$

From Envelope Theorem, we can get $\frac{d \Pi_{B}^{*}}{d m}=(p-s) E \min \left(q_{B}^{*}, x\right)>0$, and $\frac{d^{2} \Pi_{B}^{*}}{d m^{2}}=$ $(p-s) \bar{F}\left(q_{B}^{*}\right) \frac{d q_{B}^{*}}{d m}>0$. Thus $\Pi_{B}^{*}$ is increasing convex in $m$.

Proof of Proposition 3 After calculation, we can get

$$
\begin{aligned}
\Pi_{E R}^{*}= & (p-s)\left\{q_{E R}^{*}-\left[\bar{G}\left(\beta_{R}\right)+m G\left(\beta_{R}\right)\right] \int_{0}^{\frac{q_{E R}^{*}}{\bar{G}\left(\beta_{R}\right)+m G\left(\beta_{R}\right)}} F(x) d x\right\} \\
& -(c-s) q_{E R}^{*}-(p-s)(1-m)\left\{q_{E R}^{*}-\bar{G}\left(\beta_{R}\right) \int_{0}^{\frac{q_{E R}^{*}}{\bar{G}\left(\beta_{R}\right)}} F(x) d x\right\} .
\end{aligned}
$$

From envelope theorem, we can immediately have

$$
\frac{d \Pi_{E R}^{*}}{d \beta_{R}}=\frac{\partial \Pi_{E R}^{*}}{\partial \beta_{R}}=(p-s)(1-m) g\left(\beta_{R}\right) \int_{\frac{q_{E R}^{*}}{\bar{G}\left(\beta_{R}\right)+m G\left(\beta_{R}\right)}}^{\frac{q_{E R}^{*}}{\bar{G}\left(\beta_{R}\right)}} x f(x) d x>0 .
$$

By noting that $d \beta_{R} / d t=1-m \geq 0$, we have $d \Pi_{E R}^{*} / d t>0$.

In additive have that

$$
\begin{aligned}
\frac{d \Pi_{E R}^{*}}{d s} & =\frac{\partial \Pi_{E R}^{*}}{\partial s} \\
& =\left[\bar{G}\left(\beta_{R}\right)+m G\left(\beta_{R}\right)\right] \int_{0}^{\frac{q_{E R}^{*}}{\bar{G}\left(\beta_{R}\right)+m G\left(\beta_{R}\right)}} F(x) d x+(1-m) E \min \left[q_{E R}^{*}, \bar{G}\left(\beta_{R}\right) x\right]>0 .
\end{aligned}
$$


Proof of Proposition 4 If $\beta_{R}=0\left(\right.$ i.e., $t=0$ ), then we have that $\Pi_{E R}^{*}=\Pi_{R}^{*}$, which together with $\beta_{R} \geq 0$ and $d \Pi_{E R}^{*} / d \beta_{R}>0$ lead to $\Pi_{E R}^{*} \geq \Pi_{R}^{*}$. In a similar fashion, we can get that $\Pi_{E R}^{*}<\Pi_{B}^{*}$.

Proof of Proposition 5 We can easily have $\frac{d q_{E Q}^{*}}{d m}=F^{-1}\left(\frac{p-c}{p-s}\right), \frac{d^{2} q_{E Q}^{*}}{d m^{2}}=0, \frac{d \Pi_{E Q}^{*}}{d m}=(p-$ s) $\int_{0}^{F^{-1}\left(\frac{p-c}{p-s}\right)} x f(x) d x$ and $\frac{d^{2} \Pi_{E Q}^{*}}{d m^{2}}=0$. Thus, $q_{E Q}^{*}$ and $\Pi_{E Q}^{*}$ all linear increasing in $m$.

Proof of Proposition 6 (1) Comparison of inventory quantity. When $m=\underline{m}$, we have $q_{E Q}^{*}=$ $\underline{m} F^{-1}\left(\frac{p-c}{p-s}\right)>q_{R}^{*}=0$; when $m=1$, we have $q_{E Q}^{*}=q_{R}^{*}$. By noting that $q_{E Q}^{*}$ is linear increasing in $m$ whereas $q_{R}^{*}$ is increasing concave in $m$, then there are two possible outcomes between $q_{E Q}^{*}$ and $q_{R}^{*}$ : (i) for all $m$, then $q_{E Q}^{*}>q_{R}^{*}$; (ii) there exists a threshold $m^{*}$, when $m \leq m^{*}$, then $q_{E Q}^{*} \geq q_{R}^{*}$; when $m>m^{*}$, then $q_{E Q}^{*}<q_{R}^{*}$. As noted, $\frac{d q_{E Q}^{*}}{d m}$ is a constant, whereas $\frac{d q_{R}^{*}}{d m}$ is decreasing in $m$. For $m=1$, if $\frac{d q_{E Q}^{*}}{d m}<\frac{d q_{R}^{*}}{d m}$, case (i) is satisfied; if $\frac{d q_{E Q}^{*}}{d m}>\frac{d q_{R}^{*}}{d m}$, case (ii) holds.

Based on $\left.\frac{d q_{E Q}^{*}}{d m}\right|_{m=1}=\left.\frac{d q_{R}^{*}}{d m}\right|_{m=1}$, we can get $F^{-1}(1-z) f\left[F^{-1}(1-z)\right]=z$, where $z=\frac{c-s}{p-s}$. From this equation, the unique solution $z_{0}$ is obtained. Substituting $z_{0}$ in $z$ above, we obtain that $s^{E Q}=p-\frac{p-c}{1-z_{0}}$. Hence, if $s<s^{E Q}$, we have $\frac{d q_{E Q}^{*}}{d m}<\frac{d q_{R}^{*}}{d m}$ and $q_{E Q}^{*}>q_{R}^{*}$; if $s \geq s^{E Q}$, we can obtain that $\frac{d q_{E Q}^{*}}{d m} \geq \frac{d q_{R}^{*}}{d m}$. Correspondingly, case (ii) is satisfied.

(2) Comparison of optimal profit. When $m=\underline{m}$, we have $\Pi_{R}^{*}=0$ and $\Pi_{E Q}^{*}=(p-$ s) $\underline{m} \int_{0}^{F^{-1}\left(\frac{p-c}{p-s}\right)} x f(x) d x>0$. When $m=1$, we have $q_{E Q}^{*}=q_{R}^{*}$ and $\Pi_{E Q}^{*}=\Pi_{R}^{*}$. By noting that $\Pi_{E Q}^{*}$ is linear increasing in $m$ whereas $\Pi_{R}^{*}$ is increasing convex in $m$, we can show that $\Pi_{E Q}^{*}>\Pi_{R}^{*}$.

Proof of Proposition 8 Differentiating the profit function $\Pi_{P}^{*}$ w.r.t. $\lambda$, we can now get

$$
\begin{aligned}
\frac{d \Pi_{P}^{*}}{d \lambda}= & (p-s)\left\{(1-m) \theta(\lambda)+[m+(1-m) \lambda] \theta^{\prime}(\lambda)\right\} \int_{0}^{\frac{q_{P}^{*}}{\theta(\lambda)}} x f(x) d x \\
& +(c-s) q_{P}^{*} \frac{1-m}{m+(1-m) \lambda}>0 .
\end{aligned}
$$

By noted that $\theta(\lambda) \geq 1$, then we can get that $\left.\Pi_{P}^{*}\right|_{\lambda=1}=\left.\theta(\lambda)\right|_{\lambda=1} \Pi_{B}^{*} \geq \Pi_{B}^{*}$.

Assume that $\left.\theta(\lambda)\right|_{\lambda=0}=1$, we can obtain that $\left.\Pi_{P}^{*}\right|_{\lambda=0}=m(p-$ s) $\int_{0}^{\bar{F}^{-1}\left[\frac{c-s}{m(p-s)}\right]} x f(x) d x=\Pi_{R}^{*}$.

Noted that $\frac{\left.d \Pi_{P}^{*}\right|_{\lambda=0}}{d m}=\frac{d \Pi_{R}^{*}}{d m}>0$, and $\left.\Pi_{P}^{*}\right|_{\lambda=0, m=1}=\Pi_{B}^{*}$, we can get that $\left.\Pi_{P}^{*}\right|_{\lambda=0}<\Pi_{B}^{*}$ if $m<1$.

\section{References}

Akçay, Y., Boyac1, T., \& Zhang, D. (2013). Selling with money-back guarantees: The impact on prices, quantities, and retail profitability. Production and Operations Management, 22, 777-791.

Alexandrescu, A., Butincu, C. N., \& Craus, M. (2017). Recommending products and services belonging to online businesses using intelligent agents. Service Science, 9, 338-348. 
Altug, M. S., \& Aydinliyim, T. (2016). Counteracting strategic purchase deferrals: The impact of online retailers' return policy decisions. Manufacturing and Service Operation Management, 18, 376-392.

Avery, J., Steenburgh, T., Deighton, J., \& Caravella, M. (2012). Adding bricks to clicks: Predicting the patterns of cross-channel elasticities over time. Journal of Marketing, 76, 96-111.

Balakrishnan, A., Sundaresan, S., \& Zhang, B. (2014). Browse-and-switch: Retail-online competition under value uncertainty. Production and Operations Management, 23, 1129-1140.

Bell, D. R., Gallino, S., \& Moreno, A. (2018). Offline showrooms in omnichannel retail: Demand and operational benefits. Management Science, 64, 1629-1651.

Chen, W. (2019). Is there no worry about returning goods after buying freight insurance? Youth times, October 31, A15. http://www.qnsb.com/fzepaper/site1/qnsb/html/2019-10/31/content_681573.htm.

Chou, M. C., Sim, C., \& Yuan, X. (2020). Policies for inventory models with product returns forecast from past demands and past sales. Annals of Operations Research. https://doi.org/10.1007/s10479-020-0354 $5-4$.

Cohen, M. C. (2017). Big data and service operations. Production and Operations Management. https://doi. org/10.1111/poms.12832.

Crocker, K. J., \& Letizia, P. (2014). Optimal policies for recovering the value of consumer returns. Production and Operations Management, 23, 1667-1680.

Dijkstra, A. S., Van der Heide, G., \& Roodbergen, K. J. (2017). Transshipments of cross-channel returned products. International Journal of Production Economics. https://doi.org/10.1016/j.ijpe.2017.09.001.

Dukes, A., \& Zhu, Y. (2019). Why customer service frustrates consumers: Using a tiered organizational structure to exploit hassle costs. Marketing Science. https://doi.org/10.1287/mksc.2019.1149.

Ertekin, N. (2018). Immediate and long-term benefits of in-store return experience. Production and Operation Management, 27, 121-142.

Ettl, M., Harsha, P., Papush, A., \& Perakis, G. (2019). A data-driven approach to personalized bundle pricing and recommendation. Manufacturing \& Service Operations Management. https://doi.org/10.1287/msom. 2018.0756.

Fan, W., Liu, J., Zhu, S., \& Pardalos, P. M. (2018). Investigating the impacting factors for the healthcare professionals to adopt artificial intelligence-based medical diagnosis support system (AIMDSS). Annals of Operations Research. https://doi.org/10.1007/s10479-018-2818-y.

Fosso Wamba, S., Edwards, A., \& Akter, S. (2019). Social media adoption and use for improved emergency services operations: The case of the NSW SES. Annals of Operations Research, 283, 225-245.

Gallino, S., \& Moreno, A. (2018). The value of fit information in online retail: Evidence from a randomized field experiment. Manufacturing \& Service Operations Management, 20, 767-787.

Gao, F., \& Su, X. (2017). Online and offline information for omnichannel retailing. Manufacturing \& Service Operations Management, 19, 84-98.

Hsiao, L., \& Chen, Y. (2012). Returns policy and quality risk in e-business. Production and Operation Management, 21, 489-503.

Hu, X., Wan, Z., \& Murthy, N. N. (2019). Dynamic pricing of limited inventories with product returns. Manufacturing \& Service Operations Management, 21, 501-518.

Hua Ying capital. (2018). Artificial intelligence reshapes the retail industry! It's time to adapt or die. Touzhong Network. April 10. https://www.chinaventure.com.cn/cmsmodel/news/detail/325144.html.

Iyer, G., \& Kuksov, D. (2012). Competition in consumer shopping experience. Marketing Science, 31, $913-933$.

Jing, B. (2018). Showrooming and Webrooming: Information externalities between online and offline sellers. Marketing Science, 37, 469-483.

Kim, Y., \& Krishnan, R. (2015). On product-level uncertainty and online purchase behavior: An empirical analysis. Management Science, 61, 2449-2467.

Kumar, V., Umashankar, N., Kim, K. H., \& Bhagwat, Y. (2014). Assessing the influence of economic and customer experience factors on service purchase behaviors. Marketing Science, 33, 673-692.

Lake, K. (2018). Stitch Fix's CEO on selling personal style to the mass market. Harvard Business Review, 96, 35-40.

Letizia, P., Pourakbar, M., \& Harrison, T. (2018). The impact of consumer returns on the multichannel sales strategies of manufacturers. Production and Operations Management, 27, 323-349.

Leung, E., Paolacci, G., \& Puntoni, S. (2018). Man versus machine: Resisting automation in identity-based consumer behavior. Journal of Marketing Research, 55, 818-831.

Li, L., Chi, T., Hao, T., \& Yu, T. (2018). Customer demand analysis of the electronic commerce supply chain using Big Data. Annals of Operations Research, 268, 113-128.

Luo, X., Tong, S., Fang, Z., \& Qu, Z. (2019). Frontiers: Machines vs. humans: The impact of artificial intelligence chatbot disclosure on customer purchases. Marketing Science, 38, 937-947.

McKinsey. (2015). China digital consumer survey report: Growing desire for choice and change. March 15. https://www.useit.com.cn/thread-8502-1-1.html. 
Meeker, M. (2016). Internet trend report 2016. June 2.

Ng, S., \& Stevens, L. (2015). Where your unwanted Christmas gifts get a second life. Wall Street Journal. December 27. http://www.wsj.com/articles/where-your-unwanted-christmas-gifts-get-a-second-life-145 1212201.

Ofek, E., Katona, Z., \& Sarvary, M. (2011). "Bricks and clicks": The impact of product returns on the strategies of multichannel retailers. Marketing Science, 30, 42-60.

Overseas Chinese News Network. (2015). Some people are happy and others are sad when returning goods in the United States. http://m.sohu.com/a/19783164_108995. June 23, 2015.

Pauwels, K., \& Neslinb, S. A. (2015). Building with bricks and mortar: The revenue impact of opening physical stores in a multichannel environment. Journal of Retailing, 91, 182-197.

Samorani, M., Alptekinoğlu, A., \& Messinger, P. P. (2019). Product return episodes in retailing. Service Science, 11, 263-278.

Shang, G., Ghosh, B. P., \& Galbreth, M. R. (2017). Optimal retail return policies with wardrobing. Production and Operations Management, 26, 1315-1332.

Shulman, J. D., Coughlan, A. T., \& Canan Savaskan, R. (2009). Optimal restocking fees and information provision in an integrated demand-supply model of product returns. Manufacturing and Service Operation Management, 11, 577-594.

Sivamani, S., Choi, J., \& Cho, Y. (2018). A service model for nutrition supplement prediction based on Fuzzy Bayes model using big data in livestock. Annals of Operations Research, 265, 257-268.

Sprague, B., Steger, T., \& Douthit, D. (2008). Big trouble with no trouble found returns: Confronting the high cost of customer returns. Research Report.

$\mathrm{Su}, \mathrm{X}$. (2009). Consumer returns policies and supply chain performance. Manufacturing and Service Operation Management, 11, 595-612.

Tran, T., Gurnani, H., \& Desiraju, R. (2018). Optimal design of return policies. Marketing Science, 37, $649-667$.

Xiao, T., \& Shi, J. (2016). Consumer returns reduction and information revelation mechanism for a supply chain. Annals of Operations Research, 240, 661-681.

Xu, K., Chan, J., Ghose, A., \& Han, S. P. (2017). Battle of the channels: The impact of tablets on digital commerce. Management Science, 63, 1469-1492.

You, T. (2017). HAOMAIYI virtual fitting: Let each consumer have their own artificial intelligence fashion consultant. May 10. https://www.sohu.com/a/139458214_472705.

Zhen, Y. (2017). Stitch Fix's US\$4 billion valuation is based on this approach. November 15. http://news.efu. com.cn/newsview-1241371-1.html.

Publisher's Note Springer Nature remains neutral with regard to jurisdictional claims in published maps and institutional affiliations. 